\title{
LA PÓLIS GRIEGA ANTIGUA Y EL MODERNO CONCEPTO DE ESTADO
}

Julián Gallego ${ }^{1}$

El análisis de Diego Paiaro, si bien centrado en la situación de la democracia ateniense, se encuadra en un campo de indagación que, como bien reconoce el autor, implica el abordaje del problema más general de la pólis griega, la utilidad del concepto de Estado en relación la misma, el rol del parentesco, y, eventualmente, la pregunta acerca de si la conformación de la pólis entraña al mismo tiempo el surgimiento de un tipo específico de Estado.

En líneas generales, la noción de Estado se ha aplicado a la pólis de distintas maneras, pero siempre reconociendo explícita o implícitamente su carácter estatal, empleando diversos modos para concretarlo (Estado griego, ciudad-Estado, Estadopólis, Estado-ciudadano). ${ }^{2} \mathrm{Al}$ mismo tiempo, uno de los inconvenientes muchas veces señalado por los estudiosos es la imposibilidad de separar claramente Estado y sociedad en el marco de la pólis griega. Sin embargo, en los últimos años se ha planteado un fuerte debate a raíz de la intervención de Moshe Berent (1996, 1998, 2000a, 2000b, 2004, 2006), que a través de varios artículos ha sostenido que la pólis no fue un tipo de Estado sino una sociedad o comunidad sin Estado. 3 El punto central de su razonamiento radica en que la pólis sólo tuvo un aparato coercitivo público rudimentario y, por consiguiente, la característica del monopolio de la violencia como el elemento definitorio central de un Estado estaría prácticamente ausente:4 no habría fuerza pública que respaldara e hiciera cumplir las leyes; no existiría un ejército con

\footnotetext{
${ }^{1}$ Profesor de Historia Antigua Clásica en la Universidad de Buenos Aires e Investigador Principal del Consejo Nacional de Investigaciones Científicas y Técnicas de Argentina (CONICET). E-mail: julianalejandrogallego@hotmail.com

2 Para sendas perspectivas integrales sobre el problema, ver Sakellariou (1989); Hansen (1998; 2006).

3 Los argumentos y contenidos que el autor vuelca en estos artículos proceden de su tesis doctoral inédita, Berent (1994). Ciertamente, Berent (200ob, p. 8-9) no equipara a la pólis con una comunidad tribal: "Es importante señalar que la pólis, aunque sin estado, era diferente de las comunidades sin estado estudiadas por los antropólogos, porque no era tribal... [L]a pólis tenía una estructura política y económica mucho más compleja que las sociedades acéfalas (tribales)...”.

4 Pueden hallarse coincidencias, o al menos reparos que van en la misma dirección que los planteos de Berent, en Osborne (1985, p. 7) y Morris (1991, p. 44). Para destacar la peculiaridad de la pólis como una sociedad cara-a-cara y sus significativas diferencias respeto de los Estados altamente centralizados, que generan burocracias administrativas, militares y religiosas, se ha recurrido a las conceptualizaciones de Gellner (1988a, p. 23-24, 28, 1988b, p. 22). Al respecto, ver asimismo Herman (1987, p. 162-163, 2006, p. 216-257); Morris (1991, p. 46-50, 2009, p. 136-141); Anderson (2009, p. 2-4).
} 
presencia permanente (excepto en contadas excepciones) al que pudiera apelarse haciéndolo intervenir para establecer y/o controlar el orden interno.

La perspectiva de Berent ha generado importantes intervenciones a favor y en contra de sus ideas. Entre estas últimas, la más extensa y argumentada es la postura de Mogens Hansen (2002),5 quien retoma sus elaboraciones previas realizadas en el contexto del Copenhagen Polis Centre. El autor revisa exhaustivamente un conjunto de cuestiones para reafirmar lo que a continuación apuntamos en apretada síntesis. $\mathrm{Si}$ bien hablar de la pólis implicaba referirse a los ciudadanos que la integraban, esto no inhibía que para los griegos apareciera habitualmente como un poder impersonal abstracto ubicado por sobre los dirigentes y los dirigidos. Por otra parte, Berent incurre en una gran simplificación al reducir el concepto de Estado desarrollado por Max Weber únicamente al monopolio de la fuerza, pues en sí mismo esto no constituye un Estado. Debe considerarse el gobierno, el territorio y la población para poder afirmar o negar si una comunidad es un Estado. Hansen pone de relieve que la pólis cumplía con estos tres requisitos y, por ende, era un Estado en la medida en que tenía un gobierno que imponía la ley y el orden dentro de un territorio y sobre una población, para lo cual contaba con diversos recursos que le permitían, prácticamente, detentar el monopolio del uso legítimo de la coerción (fuerza militar casi permanente; administración de justicia; coacción y consenso para generar respeto a las leyes; relaciones con otras comunidades; todo esto llevado a cabo por magistrados seleccionados para tales fines; esto no quedaba anulado por la falta de patrullas policiales, que implicaba tener que recurrir al accionar privado de los propios ciudadanos para capturar a un criminal y/o hacer cumplir una sentencia). ${ }^{6}$

A partir de los análisis precedentes y a los fines de las puntualizaciones que pretendemos plantear, haremos hincapié aquí en un problema conceptual que merece atención siguiendo para ello la interpretación de Nicole Loraux (2007, p. 251) en su lectura de Pierre Clastres:

\footnotetext{
5 Véase la respuesta en Berent (2004). Para balances sobre estas dos perspectivas, cf. Faraguna (2000); Miyazaki (2007). Se hallarán críticas a Berent en Grinin (2004, cf. 2003, 2008) y van der Vliet (2005, cf. 2008), con la réplica en Berent (2006). Breves reflexiones sobre la cuestión en Cartledge (2000, p. 17-18, 2009, p. 13, 17), que acepta la propuesta de Berent, y en Herman (2006, p. 227-228) y Hall (2007, p. 119-120, 2013, p. 10-11), que rechazan la visión de Berent. Cf. López Barja (2012, p. 83) quien no acuerda con Berent, pero cree por otros motivos que la ciudad antigua no fue un Estado.

6 Respecto del modo en que Hansen construye su argumentación, es pertinente la puntualización de Miyazaki (2007, p. 89, n. 10): "Pero todo lo que este tipo de comparación nos trae son similitudes y diferencias 'aparentes' o 'superficiales', a menos que examinemos cómo estos elementos se interrelacionan unos con otros y cómo funcionan en sus interrelaciones. No me parece que Hansen sea muy consciente de esto".
} 
Si pólis es el nombre griego de la colectividad política, el sintagma "ciudad-estado" es el modo de traducción para los historiadores. Sintagma delicado: al adjuntar "estado" a "ciudad" para evitar toda confusión de la pólis con la ciudad, que es solamente el centro urbano, el historiador intenta por lo general precisar que la ciudad griega no es un estado sino una colectividad que se expresa bajo el modelo del nosotros, idealmente y -así lo espera- en la realidad (lograda inscripción arcaica que comienza por "Nosotros, ciudadanos, hemos decidido...", icuántas especulaciones tu descubrimiento ha venido a corroborar!). Desearíamos probablemente que el historiador demasiado sereno no fuera tan ingenuo de creer que el agregado de la palabra estado pueda alguna vez ser un gesto neutro.

Este es el problema fundamental: ¿por qué para pensar cómo una comunidad se manifiesta afirmando su identidad bajo el modo del "nosotros" es necesario recurrir al concepto de Estado? De modo natural, tendemos a pensar que las sociedades se organizan y adquieren coherencia y unidad en tanto que tales a partir de la operatoria del Estado. Está tan arraigado en nuestro pensamiento, está tan instalado en nuestro sentido común, que asumimos sin cortapisas que el Estado opera como factor fundamental de cohesión de las sociedades. Nos planteamos el problema de sus orígenes, como cuando inmediatamente pensamos que el surgimiento de la pólis no es otra cosa que el surgimiento del Estado griego. Y cuando nos enfrentamos a sociedades para las que la evidencia no acredita la presencia del Estado, las clasificamos como sociedades sin Estado o preestatales. De tal forma, solemos suponer su inevitabilidad; y cuando su existencia como cosa no puede ser comprobada, consideramos a esas formaciones sociales en virtud de una carencia, no de una positividad. Aventurándonos en un terreno que es ajeno al de nuestra especialidad, mencionaremos también que, en tanto que la soberanía ha sido un rasgo definitorio del Estado, ante la supuesta dispersión de los poderes públicos se habla entonces de fragmentación de la soberanía en referencia a la desaparición del Estado o a la condición minimalista que adquiere. Tal ha sido nuestra condición de época que pensar con Estado se nos ha hecho ya costumbre: el Estado se nos ha vuelto casi una segunda naturaleza.

No es ninguna novedad para nadie el papel del Estado-nación como aglutinante de las sociedades bajo el imperio del capital. Al menos por intuición, hoy sabemos que esto ya no se sostiene en lo que respecta a la primacía del Estado-nación como ámbito consolidado de funcionamiento del capital. Es metodológicamente pertinente aplicar a este proceso el mismo criterio de fluidez que Marx y Engels (2005, p. 159, cf. p. 157-161) enunciaban en relación con el ascenso de la burguesía: revolución 
continua de todas las relaciones sociales; inquietud y movimientos constantes; ruptura de las relaciones antiguas; rápido ocaso de las nuevas; todo lo sólido se desvanece en el aire. ¿Es el Estado una estructura cuya singular solidez como fundamento de la consistencia de la sociedad le permita escapar al desfondamiento incesante que la propia dinámica del capital produce? En su libro Pensar sin Estado, Ignacio Lewkowicz (2004, p. 10-11) ha forjado sobre este punto una tesis fundamental: el Estado como factor de cohesión social se encuentra sometido a la fluidez permanente del capital. Como efecto de la actual primacía del capital financiero, pero también de los sucesos argentinos de los años 2001 y 2002, Lewkowicz postula la emergencia de una nueva condición de pensamiento:

Pensar sin Estado es una contingencia del pensamiento - y no del estado -; nombra una condición de época como configuración posible de los mecanismos de pensamiento. Pensar sin Estado no refiere tanto a la cesación objetiva del estado como al agotamiento de la subjetividad y el pensamiento estatales. Por eso podemos poner en duda que haya desaparecido el estado; podemos verificar enormes organizaciones técnicas, militares, administrativas con un vasto poder de influencia. Pero influencia no es soberanía; y la subjetividad estatal no arraigaba en la mera existencia del estado sino en su soberanía. [...] Tras el desfondamiento varía la condición del estado. [...] El estado es un término importante entre otros términos de las situaciones, pero no es la condición fundante del pensamiento. El estado no desaparece como cosa; se agota la capacidad que esa cosa tenía para instituir subjetividad y organizar pensamiento. 7

En este sentido, no se trata entonces de suponer una identidad entre Estado y sociedad en la pólis, situación que, según sugerían Victor Ehrenberg (1960, p. 89) y Jean-Pierre Vernant (1965, p. 34-35, n. 10), habría llevado a los griegos a una contradicción infranqueable entre el carácter unitario del Estado y el carácter fragmentario de la sociedad, contraste que los propios griegos nunca habrían llegado a comprender acabadamente debido a que, ya sea en el plano de la acción, ya sea en el del pensamiento, jamás distinguieron entre un aspecto y el otro. ${ }^{8}$

\footnotetext{
${ }_{7}$ Sztulwark (2006) ha planteado que Pensar sin Estado es tanto una denuncia, cuanto una ambigüedad y una orientación: denuncia un cambio de estatuto en la relación entre pensamiento y poder; hay una ambigüedad en el "sin Estado" porque no se trata de predicar su inexistencia sino de pensar a partir del hecho de que el Estado ya no determina nuestros modos de pensar; orienta a pensar las situaciones a partir de su potencia inmanente, sin necesidad de fijar el pensamiento a partir de una toma de posición con respecto al Estado.

8 Este tema también ha sido señalado por Castoriadis (1997, p. 203). Recientemente, esta cuestión ha sido abordada con exhaustividad por Anderson (2009, p. 5-8). Meier (1985, p. 28-29) ha planteado la
} 
Tampoco sucede que la pólis griega operase como una sociedad contra el Estado, pero no por los motivos que esgrimía Pierre Clastres (1978) al separar el comportamiento indígena del griego (Loraux, 2007; Richir, 2007; cf. Campagno, 1998, 2014). ¿Qué es, pues, lo que se nos impone de la condición postulada como "pensar sin Estado"? Es sobre esta circunstancia nueva de pensamiento, habilitada por la tesis acerca del desfondamiento de la solidez asignada al Estado, sobre lo que ahora nos queremos interrogar en función de pensar el modelo griego del "nosotros", para el que se recurre al concepto de Estado pero que paradójicamente, según Loraux, no es un Estado sino una colectividad.

Todas estas cuestiones son reexaminadas por Diego Paiaro en su análisis sobre la democracia ateniense, proponiendo una penetrante interpretación en la que el Estado aparece como una función o una lógica, antes que como una objetivación o una materialidad. Se trata, en realidad, de una doble lógica conforme a la cual, por un lado, la propia comunidad de ciudadanos funcionaba como un Estado en relación con los excluidos de la ciudadanía (mujeres, esclavos, metecos, extranjeros, integrantes de ciudades sometidas al imperialismo), garantizando así su dominación y explotación, y, por otro lado, dentro del cuerpo político las relaciones entre los incluidos en la ciudadanía implicaban un funcionamiento asimilable al de una comunidad sin Estado (aunque no de la manera postulada por Berent para el conjunto de la pólis), o, siguiendo a Clastres, cabe decir que entre los ciudadanos atenienses operaba el principio de la sociedad contra el Estado, en la medida en que la configuración de los vínculos políticos inhibía el desarrollo de relaciones jerárquicas y formas de coerción entre los miembros de pleno derecho de la pólis. ${ }^{9}$ Su perspectiva tiene un indudable valor hermenéutico puesto que nos ubica fuera de una dicotomía muy conocida, según la cual la presencia de instituciones estatales se corresponde con la de pautas políticas y la ausencia de aquéllas supone el predominio de una lógica de parentesco propia de un ámbito aldeano.

necesidad de separar conceptualmente la pólis respecto del Estado moderno; Starr (1986, p. 44-45), si bien no prescinde de la noción de Estado, en parte por inercia, indica igualmente la diferencia fuerte entre la pólis y el Estado moderno; para Rahe (1994, p. 16 y 234-235, n. 10), no hubo Estado griego, ni por ende distinción entre Estado y sociedad.

9 Afirma Paiaro (2011b, p. 232): “[Berent] confunde la forma privada en que la coacción entra en escena en la pólis con la ausencia de Estado. Hemos visto que esa forma privada no estaba enteramente librada a la voluntad del individuo sino que se hallaba regulada, limitada e incluso juzgada por la pólis. Por otro lado, analizamos la movilización militar de la ciudadanía como la fuerza coactiva más importante de la ciudad que constituía el respaldo tácito de los magistrados y ciudadanos encargados del control social y que, en determinados contextos de crisis, podía funcionar como órgano represivo". Cf. Paiaro (2011a, p. 320, 2012, p. 63). 
La justeza del examen de Paiaro tiene, sin embargo, una consecuencia para el planteamiento más general que él mismo realiza respecto de las dos lógicas en la democracia ateniense; en efecto, en la medida en que las formas "privadas" coactivas controladas por la pólis se aplicaban a los propios ciudadanos atenienses, entonces la lógica estatal también los incluía a ellos. Tal vez en esto radique el punto más controversial del análisis, pues en la medida en que los propios ciudadanos podían operar unos sobre otros a través de formas limitadas de coerción que la propia pólis regulaba, o a través de la movilización de los hoplitas en situaciones críticas o de stásis, entonces debería poder plantearse con precisión la presencia de la lógica estatal en el plano del funcionamiento interno de la comunidad de los ciudadanos atenienses.

Comentário recebido em 26.06.2018, aprovado em 05.07.2018.

\section{REFERÊNCIAS BIBLIOGRÁFICAS}

Anderson, Greg. The personality of the Greek state. Journal of Hellenic Studies, 129, 2009, p. 1-22.

Berent, Moshe. The Stateless Polis: Towards a Re-evaluation of the Classical Greek Political Community. PhD in History. Cambridge: University of Cambridge, 1994.

36-59.

. Hobbes and the 'Greek tongues'. History of Political Thought, 17, 1996, p.

. Stasis, or the Greek invention of politics. History of Political Thought, 19, 1998, p. 331-362.

Anthropology and the classics: War, violence and the stateless polis. Classical Quarterly, 50, 2000a, p. 257-289.

. Sovereignty: Ancient and modern. Polis: Journal of the Society for Greek Political Thought, 17, 200ob, p. 2-34.

. In search of the Greek state: A rejoinder to M. H. Hansen. Polis: Journal of the Society for Greek Political Thought, 21, 2004, p. 107-146.

141-163.

. The stateless polis: A reply to critics. Social Evolution \& History, 5, 2006, p.

Campagno, Marcelo. Pierre Clastres y el surgimiento del Estado: Veinte años después. Boletín de Antropología Americana, 33, 1998, p. 101-113.

. Introducción: Pierre Clastres, las sociedades contra el Estado y el mundo antiguo. In: Campagno, Marcelo (ed.) Pierre Clastres y las Sociedades Antiguas. Buenos Aires: Miño y Dávila, 2014, p. 7-34.

Cartledge, Paul. Greek political thought: The historical context. In: Rowe, Christopher; Schofield, Malcolm (eds) The Cambridge History of Greek and Roman Political Thought. Cambridge: Cambridge University Press, 2000, p. 11-22. 
University Press, 2009.

Ancient Greek Political Thought in Practice. Cambridge: Cambridge

Castoriadis, Cornelius. Imaginario político griego y moderno. In: El Avance de la Insignificancia. Traducción de A. Pignato. $1^{\mathrm{a}}$ edición 1996. Buenos Aires: Editorial Universitaria de Buenos Aires, 1997, p. 195-222.

Clastres, Pierre. La Sociedad Contra el Estado. Traducción de A. Pizarro. $1^{\text {a }}$ edición 1974. Caracas: Monte Ávila, 1978.

Ehrenberg, Victor. The Greek State. Oxford: Basil Blackwell, 1960.

Faraguna, Michele. Individuo, stato e comunità: Studi recenti sulla polis. Dike, 3, 2000, p. 217-229.

Gellner, Ernest. Naciones y Nacionalismo. Traducción de J. Seto. 1a edición 1983. Madrid: Alianza, 1988a.

. Plough, Sword and Book: The Structure of Human History. Chicago: University of Chicago Press, 1988 b.

Grinin, Leonid. The early state and its analogues. Social Evolution \& History, 2, 2003, p. 131-176.

. Democracy and early state. Social Evolution \& History, 3, 2004, p. 93-149.

Early state in the classical world: Statehood and ancient democracy. In: Grinin, Leonid; Beliaev, Dmitri; Korotayev, Andrei (eds) Hierarchy and Power in the History of Civilizations: Ancient and Medieval Cultures. Moscow: Uchitel, 2008, p. 31-84.

Hall, Jonathan. A History of the Archaic Greek World, ca. 120o-479 B.C.E. Malden: Wiley-Blackwell, 2007.

. The rise of state action in the archaic age. In: Beck, Hans (ed.) A Companion to Ancient Greek Government. Malden: Wiley-Blackwell, 2013, p. 9-21.

Hansen, Mogens. Polis and City-state: An Ancient Concept and Its Modern Equivalent. Copenhagen: Det Kongelige Danske Videnskabernes Selskab, 1998.

. Was the polis a state or a stateless society? In: Nielsen, Thomas (ed.) Even More Studies in the Ancient Greek Polis. Stuttgart: Franz Steiner, 2002, p. 17-47.

Polis: An Introduction to the Ancient Greek City-state. Oxford: Oxford University Press, 2006.

Herman, Gabriel. Ritualised Friendship and the Greek City. Cambridge: Cambridge University Press, 1987.

University Press, 2006.

Morality and Behaviour in Democratic Athens. Cambridge: Cambridge

Lewkowicz, Ignacio. Pensar sin Estado: La Subjetividad en la Era de la Fluidez. Buenos Aires: Paidós, 2004.

López Barja, Pedro. La ciudad antigua no era un Estado. In: Dell'Elicine, Eleonora; Francisco, Héctor; Miceli, Paola; Morin, Alejandro (eds) Pensar el Estado en las Sociedades Precapitalistas: Pertinencia, Límites y Condiciones del Concepto de Estado. Los Polvorines: Universidad Nacional de General Sarmiento, 2012, p. 79-92.

Loraux, Nicole. Notas sobre el uno, el dos y lo múltiple. In: Abensour, Michel (ed.) El 
Espíritu de las Leyes Salvajes: Pierre Clastres o Una Nueva Antropología Política. Traducción de C. Battaglia. $1^{\text {a }}$ edición 1987. Buenos Aires: Ed. del Sol, 2007, p. 243264.

Marx, Karl; Engels, Friedrich. El Manifiesto Comunista. Ed. orig. con introd. y notas de G. S. Jones. Traducción de J. Izquierdo Martín. Madrid: Fondo de Cultura Económica, 2005.

Meier, Christian. Introducción a la Antropología Política de la Antigüedad Clásica. Traducción de J. Barrales Valladares. $1^{\mathrm{a}}$ edición 1984. México: Fondo de Cultura Económica, 1985

Miyazaki, Makoto. Public coercive power of the Greek polis: On a recent debate. Bulletin of the Institute for Mediterranean Studies, 5, 2007, p. 87-100.

Morris, Ian. Burial and Ancient Society: The Rise of the Greek City-state. Cambridge: Cambridge University Press, 1991

. The greater Athenian state. In: Morris, Ian; Scheidel, Walter (eds) The Dynamics of Ancient Empires: State Power from Assyria to Byzantium. Oxford: Oxford University Press, 2009, p. 99-177.

Osborne, Robin. Demos: The Discovery of Classical Attika. Cambridge: Cambridge University Press, 1985.

Paiaro, Diego. La ciudad democrática y el poder coercitivo de la pólis. In: III Jornadas Nacionales / II Jornadas Internacionales de Historia Antigua. Actas. Córdoba: Universidad Nacional de Córdoba, 2011a, p. 312-322.

. Las ambigüedades del Estado en la democracia ateniense: Entre la libertad y la coacción. In: Campagno, Marcelo; Gallego, Julián; García Mac Gaw, Carlos (eds) El Estado en el Mediterráneo Antiguo: Egipto, Grecia, Roma. Buenos Aires: Miño y Dávila, 2011b, p. 223-242.

. Ándres gàr pólis. Algunas reflexiones acerca de los debates recientes en torno a la estatalidad de la ciudad griega antigua a la luz del caso ateniense. In: Dell'Elicine, Eleonora; Francisco, Héctor; Miceli, Paola; Morin, Alejandro (eds) Pensar el Estado en las Sociedades Precapitalistas: Pertinencia, Límites y Condiciones del Concepto de Estado. Los Polvorines: Universidad Nacional de General Sarmiento, 2012, p. 51-77.

Rahe, Paul. Republics Ancient and Modern: 1, The Ancient Régime in Classical Greece. Chapel Hill: University of North Carolina Press, 1994.

Richir, Marc. Algunas reflexiones epistemológicas preliminares acerca del concepto de sociedades contra el Estado. In: Abensour, Michel (ed.) El Espíritu de las Leyes Salvajes: Pierre Clastres o Una Nueva Antropología Política. Traducción de C. Battaglia. $1^{\text {a }}$ edición 1987. Buenos Aires: Ed. del Sol, 2007, p. 121-134.

Sakellariou, M. B. The Polis-state: Definition and Origin. Athens: Research Centre for Greek and Roman Antiquity, National Hellenic Research Foundation, 1989.

Starr, Chester. Individual and Community: The Rise of the Polis, 8oo-5oo B.C. New York: Oxford University Press, 1986.

Sztulwark, Diego. ¿Pensar sin Estado?, Campo Grupal, 83, 2006, p. 4-5.

Van der Vliet, Edward. Polis: The problem of statehood. Social Evolution \& History, 4, 2005, p. 120-150. 
Evolution \& History, 7, 2008, p. 197-221.

Vernant, Jean-Pierre. Los Orígenes del Pensamiento Griego. Traducción de M. Ayerra. $1^{\mathrm{a}}$ edición 1962. Buenos Aires: Editorial Universitaria de Buenos Aires, 1965. 